Editorial

\title{
Laryngeal cancer and asbestos
}

The hypothesis that exposure to asbestos is a cause of cancer of the larynx was generated from a description of "the cohort approach (in industrial health studies), with special reference to an asbestos company." Some 1500 white employees in 1938 or 1939 were followed up to mid-1960; there had been 186 deaths (excluding eight war casualties and one death at sea) at ages 25-64, an excess of 41 over expectation based on mortality in Ohio, 1950-60. The excess was made up of 28 deaths recorded as due to asbestosis and 31 to neoplasms, counterbalanced by a shortfall of 18 deaths from other causes. Among men, there had been excesses totalling 24 deaths due to malignant neoplasms, 10 of the respiratory system: the numbers of deaths observed and expected were: 15 and 5.42 for lung cancer; 1 and 0.38 for cancer of the larynx; and 0 and $0 \cdot 14$ for other respiratory malignancies. This tiny excess of laryngeal cancer could suggest a link with exposure to asbestos only because of the obvious biological plausibility that an agent which can cause lung cancer could also cause cancer of the larynx.

The best method for investigating the hypothesis is not obvious. Thus cohort mortality studies, so fruitful for investigating lung cancer, are not necessarily the best epidemiological approach to cancer of the larynx, if only because the case fatality rate is so low. ${ }^{2}$ Nevertheless, much can be ascertained about asbestos exposure: usually, the type(s) of fibre, and the degree of exposure, at least in terms of its duration; on the other hand, smoking and drinking habits are usually unknown. The alternative, casereferent, approach might appear more attractive, particularly as laryngeal cancer is so rare; however, it suffers from many potential difficulties, not least that the recording of exposure histories has usually to be without the possibility of blinding the investigators and so is a potential source of serious bias. Further, details of exposure to asbestos (even its duration let alone its intensity and the fibre type) are seldom obtainable. On the other hand, some information may often be obtained about exposure to other carcinogens known or suspected.

On the two earliest case-referent studies, in Liverpool and Toronto, ${ }^{34}$ Doll and Peto have pointed out that: "The gross associations that were observed ... cannot be due to chance and are so different from those observed subsequently that one must suspect that they were inflated by some aspect of the methodology employed,"'s and methodological flaws have been identified (FDK Liddell, unpublished data). In Liverpool smoking habits had been assessed, although the authors did not consider tobacco a risk factor: there had been more smoking among cases than among referents but, as implied by Rothman et al, no adjustment is possible from the published material. ${ }^{6}$ In Toronto inquiries were made about both smoking and alcohol consumption; Rothman $e t$ al correctly provided an estimate of relative risk (RR) among smokers (there had been no case among nonsmokers) but did not mention the reported lack of association between laryngeal cancer and exposure to alcohol.

Rothman et al in emphasising the importance of both tobacco and alcohol in the aetiology of laryngeal cancer, remarked on the "striking linearity" of the relation with smoking and the "tremendous range of effect, with the heaviest smokers experiencing more than 30 times the risk of non-smokers." The relation with alcohol was also clear, if not "tremendous," and there was an indication that the effect of each of these two risk factors might be greatest at the highest level of the other. These reviewers pointed out that, in evaluating other determinants of the disease, it was imperative to control adequately for the known risk factors, particularly when they were so strong and so prevalent.

It therefore seems surprising that they should infer that the data from Toronto indicated strongly (added emphasis) that asbestos was a risk factor for laryngeal cancer. They found corroboration from: (1) a casereferent study, adequately controlled for both smoking and alcohol consumption, but so small that the estimated RR of 2.3 was not of statistical significance, even at the $10 \%$ level; ( 2 and 3 ) two other casereferent studies, with estimated RRs of 1.75 and 1.9 , neither significant at the $10 \%$ level; (4) the Liverpool survey; (5) a cohort study (in which there were two cases, both smokers) of workers at a factory in Barking, United Kingdom, using mainly crocidolite; and (6) a cohort of United States and Canadian insulators, severely exposed to amphiboles, as well as to chrysotile, who had suffered major excesses from cancer at several sites. According to Rothman et al when intense (sic) asbestos exposure was considered, 
the estimate of RR was increased in (2) above and decreased in (3). Two reports (on miners and millers of chrysotile in Quebec and on ear, nose, and throat patients in London hospitals) of essentially negative findings on laryngeal cancer and asbestos were not mentioned. ${ }^{78}$

In their review for the Health and Safety Executive, Acheson and Gardner relied on the Liverpool and Toronto case-referent studies (bringing out the fact that 23 of 41 cases had been insulation workers, who would have been exposed to amphiboles) and three cohorts-at Barking, of North American insulators, and in Quebec. ${ }^{9}$ This last is the most reliable of all studies of asbestos workers, embracing 4463 deaths; it also has the major advantages that measures of asbestos exposure, year by year, were obtained for all 11000 subjects and smoking habits for the great majority. ${ }^{7}$ It showed a miniscule excess of laryngeal cancer, an impressive relation between risk of this cancer and amount smoked, but a slightly negative relation with cumulative exposure to asbestos (although this measure related closely to risk of lung cancer and of asbestosis). Acheson and Gardner, recognising the contradictions between the Quebec (chrysotile) findings and those from their other sources, concluded that "the weight of the published evidence suggests a causal association at least between the inhalation of mixtures of asbestos containing amphiboles and laryngeal cancer"; they added that the risk was really very small. By the time Doll and Peto reported to the Health and Safety Executive, several more studies had been published, by no means all with excesses of laryngeal cancer. Nevertheless, and even setting aside the early findings from Liverpool and Toronto, Doll and Peto argued that exposure to asbestos was a risk factor for cancer of the larynx. The latest published review (incomplete, with some inaccuracies, and in places superficial) drew the opposite conclusion, ${ }^{10}$ despite ignoring the report (also overlooked in the earlier reviews) from London hospitals. This report was of the only case-referent study in which exposure histories were taken "blind," actually before diagnosis ; smoking and drinking were confirmed as major risk factors but the asbestos RR was substantially less than unity.

In the two matched case-referent studies (other than that in Toronto) estimated RRs were greater than unity, but there was little to justify confidence in an asbestos risk for laryngeal cancer from these findings, even if one could consider all 32 "discordant pairs" as arising from one (extended) investigation: they would estimate $R R$ as $20 / 12=1.67$, for which the $p$ value is $0 \cdot 22$. In the four unmatched case-referent studies (excluding the one in Liverpool) the RRs were widely discrepant: less than unity with blind history taking; $1.3 ; 1 \cdot 4 ; 1 \cdot 8$, otherwise. No epidemiologist could be expected to provide an "average"-or "pooled"-value of risk on such $\frac{\overline{0}}{\text { ? }}$ evidence, particularly as allowance for cigarette $\Rightarrow$; smoking and alcohol consumption tended to reduce $\stackrel{\rho}{?}$ the estimate of $R R$ and widen the confidence interval.

In those cohort studies which distinguished mor- $\frac{\bar{c}}{\bar{c}}$. tality from laryngeal cancer there were excesses in $\frac{\rho}{\sigma}$ about two thirds. Even on the probably unjustifiableo assumption of homogeneity of hazard, the ratio of allis deaths observed to all expected could not be con- sidered of statistical significance at anything ap-i proaching a conventional level. Only for the Quebec $\vec{\omega}$ cohort was individual smoking habit taken into account-but not alcohol consumption. One of the numerically largest SMRs (4/1.5) was for Balangero miners and millers compared with all Italian men: there is a well above average consumption of grappar in Piedmont and so it is at least possible, particularlyog in the light of the gross SMR for cirrhosis of the liver, that the excess of 2.5 deaths from laryngeal cancer? was due to heavy exposure to alcohol. Further, $\overrightarrow{3}$ among crocidolite miners in Western Australia, the्w SMRs for alcoholism and for cirrhosis of the liverwere very high but that for laryngeal cancer was lesse? than unity.

There have also been many cohort studies of workers exposed to asbestos in which deaths froms laryngeal cancer have not been mentioned. In 25 sucho male cohorts it may be estimated that a total of more than 20 deaths from laryngeal cancer might have been expected (FDK Liddell). The fact that no death $\vec{F}$ from cancer of the larynx was reported in these cohorts has to be given due weight, especially as it has since been confirmed that in several there were noo excesses of laryngeal cancer; this view has been supported recently by Gardner. ${ }^{11}$

To summarise the findings: (1) those from the $e_{-}^{3}$ case-referent studies are mutually inconsistent; (2) those from the cohort studies, while not demon-i strably inconsistent, do not indicate a major excess of laryngeal cancer mortality in cohorts of asbestos workers; and (3) exposure-response relations were? unobtainable or equivocal. No experimental evi dence has been proffered. Estimates of the RR of cancer of the larynx obtained from the variouss surveys are so divergent that it is impossible to find an merged value without violating established epi- 고 demiological principles. The disease has seldom been found among non-smoking asbestos workers and there is no evidence as to whether these few cases were also non-drinkers.

Thus it is my opinion that the evidence on the link between exposure to asbestos and laryngeal cancer definitely fails to satisfy the criteria for causation set. by Bradford Hill. ${ }^{12}$ Furthermore, even if asbestos? cannot be disregarded as one of the subsidiary causeso of laryngeal cancer the risk of such cancer after? exposure to asbestos (relative to its absence) is lower than that for lung cancer; and as the absolute risk of 
laryngeal cancer is much less than that of lung cancer, the absolute risk attributable to asbestos must be extremely small. Finally, excesses appear quite unlikely in relation to exposure to chrysotile, although this fibre was and is by far the most common form of asbestos.

The Industrial Injuries Advisory Council (UK) has recently recommended that, on the balance of the evidence, cancer of the larynx should not be added to the schedule of prescribed diseases in respect of occupations involving exposure to asbestos. ${ }^{2}$

Department of Epidemiology and Biostatistics,

F D K LIDDELL

McGill University,

Montreal, Canada H3A 1 A2

1 Mancuso TF, Coulter EJ. Methodology in industrial health studies: the cohort approach, with special reference to an asbestos company. Arch Environ Health 1963;6:210-6.

2 Industrial Injuries Advisory Council. Report on cancer of the larynx. London: HMSO, 1989.
3 Stell PM, McGill T. Asbestos and laryngeal carcinoma. Lancet 1973;ii:416-7.

4 Morgan RW, Shettigara PT. Occupational asbestos exposure, smoking, and laryngeal carcinoma. Ann NY Acad Sci 1976; 271:308-10.

5 Doll R, Peto J. Effects on health of exposure to asbestos. Health and Safety Commission. London: HMSO, 1985.

6 Rothman KJ, Cann CI, Flanders D, Fried MP. Epidemiology of laryngeal cancer. Epidemiol Rev 1980;2:195-209.

7 McDonald JC, Liddell FDK, Gibbs GW, Eyssen GE, McDonald AD. Dust exposure and mortality in chrysotile mining, 1910-75. Br J Ind Med 1980;37:11-24.

8 Newhouse ML, Gregory NM, Shannon H. Aetiology of carcinoma of the larynx. In: Wagner JC, ed. Biological effects of mineral fibres. Lyon: International Agency for Research on Cancer, 1980. (Sci publ No 33.)

9 Acheson ED, Gardner MJ. The ill effects of asbestos upon health. In: Advisory Committee on Asbestos. Final report. Vol 2. Health and Safety Commission. London: HMSO, 1979.

10 Chan CK, Gee JBL. Asbestos exposure and laryngeal cancer: an analysis of the epidemiologic evidence. J Occup Med 1988;30:23-7.

11 Gardner MJ. A review of the available evidence for setting occupational exposure limits for asbestos. In: World Health Organisation. Occupational exposure limit for asbestos. Geneva: WHO, 1989: annex pp 1-56.

12 Hill AB. The environment and disease: association or causation? Proceedings of the Royal Society of Medicine 1965;58:295-300.

\section{Correspondence and editorials}

The British Journal of Industrial Medicine welcomes correspondence relating to any of the material appearing in the journal. Results from preliminary or small scale studies may also be published in the correspondence column if this seems appropriate. Letters should be not more than 500 words in length and contain a minimum of references. Tables and figures should be kept to an absolute minimum. Letters are accepted on the understanding that they may be subject to editorial revision and shortening.

The journal now also publishes editorials which are normally specially commissioned. The Editor welcomes suggestions regarding suitable topics; those wishing to submit an editorial, however, should do so only after discussion with the Editor. 